\title{
Real world impact of a quality improvement project to implement rapid rule out of acute coronary syndrome processes in eligible emergency department patients.
}

There is considerable evidence that accelerated rule out processes integrating clinical risk stratification and biomarker testing for suspected acute coronary syndrome (ACS) is safe. [1, 2] In the research context, implementation has resulted in significantly shorter lengths of stay for this patient cohort.[3].

In 2016, the Emergency Care Clinical Network (Department of Health and Human Services) led an evidence implementation project to implement accelerated ACS rule out processes in Victorian emergency departments (EDs).

Recommended pathways were developed for both contemporary and high sensitivity troponin assays in collaboration with the Victorian Cardiac Clinical Network. EDs participated by expression of interest. Local clinicians designed and implemented change tailored to their clinical environment and available biomarkers. Data collected was the proportion of patients eligible for an accelerated rule of pathway, the proportion in whom it was applied and total ED length of stay (LOS) (including ED observation unit if used).

Eleven EDs participated (6 metropolitan, 2 regional, 2 rural and 1 private). Data on 1385 patients was collected ( 570 pre-data and 815 post-data). Overall the proportion of patients eligible for rapid rule out process was $45.8 \%$ (95\% Cl 43.1-48.5\%). Application of accelerated rule out processes for eligible patients increased from $3.3 \%$ to $57.4 \%(p<0.001)$. Median LOS of the cohort suitable for the accelerated rule out process (whether used or not) reduced from 401 minutes to 305 minutes; effect size 96 minutes. Median LOS for the overall chest pain cohort (whether or not pathways were applied) reduced from 420 minutes to 362 minutes; effect size 58 minutes.

An estimation of the impact of this change if applied system-wide can be made by using the assumption that $2.5 \%$ of ED attendances are due to chest pain [4] and annual total ED census in Victoria was 1.7 million in 2016.[5] This equates to 42,500 chest pain patients annually. If the median LOS reduced by 1 hour (as in our project), 42,500 hours of ED capacity would be released. If an average treatment time of 3 hours per patient is assumed, [6] this change implemented across the system would release capacity to treat more than 14,000 additional patients.

Efforts to embed and further spread this initiative continue in 2017.

\section{References:}

1. Than M, Cullen L, Aldous S, Parsonage WA, Reid CM, Greenslade J et al. 2-Hour accelerated diagnostic protocol to assess patients with chest pain symptoms using contemporary troponins as the only biomarker: the ADAPT trial. J Am Coll Cardiol 2012;59(23):2091-8.

2. Than M, Aldous S, Lord SJ, Goodacre S, Frampton CM, Troughton R et al. A 2-hour

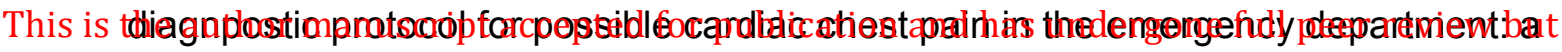

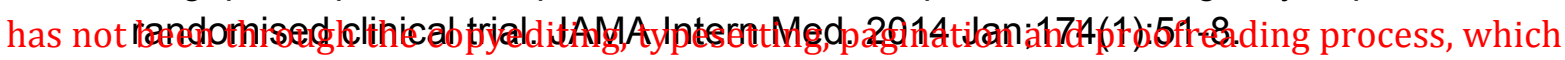

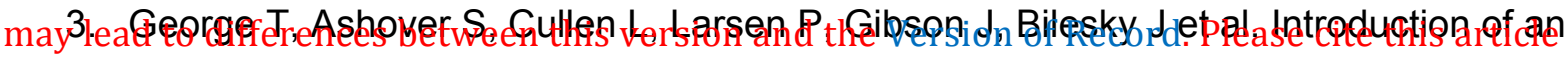
as doi: arceelerated diagnestic-protocol in the assessment of emergency department patients 
with possible acute coronary syndrome: The Nambour Short Low-Intermediate Chest pain project. Emerg Med Australas 2013; 25:340-4.

4. Goodacre S, Cross E, Arnold J, Angelini K, Capewell S, Nichol J. The health burden of acute chest pain. Heart 2005; 91:229-30.

5. Statewide - Emergency department total attendances - Quarterly Data. http://performance.health.vic.gov.au/Home/Report.aspx?ReportKey=157 Accessed March 92017

6. Australian Institute of Health and Welfare 2015. Emergency department care 201415: Australian hospital statistics. Health services series no. 65. Cat. no. HSE 168. Canberra:AlHW.http://www.aihw.gov.au/WorkArea/DownloadAsset.aspx?id=601295 53618. Accessed March 92017

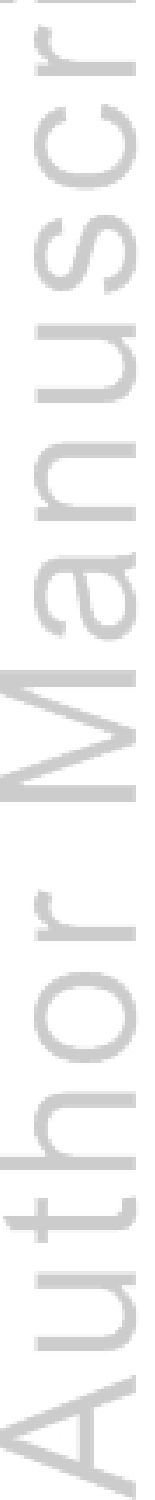

This article is protected by copyright. All rights reserved. 


\section{University Library}

\section{- M M I N E R VA \\ A gateway to Melbourne's research publications}

Minerva Access is the Institutional Repository of The University of Melbourne

Author/s:

Kelly, A-M;Pannifex, J

Title:

Real-world impact of a quality improvement project to implement rapid rule out of acute coronary syndrome processes in eligible emergency department patients

Date:

2017-06-01

\section{Citation:}

Kelly, A. -M. \& Pannifex, J. (2017). Real-world impact of a quality improvement project to implement rapid rule out of acute coronary syndrome processes in eligible emergency department patients. EMERGENCY MEDICINE AUSTRALASIA, 29 (3), pp.373-373. https:// doi.org/10.1111/1742-6723.12780.

Persistent Link:

http://hdl.handle.net/11343/292817 